\title{
Motivations of Managers in Relation to Previous Experiences on Citizen-based Community Spaces
}

\author{
Han Changhee, Satoshi Nasu \\ Department of Architecture and Building Engineering, \\ Tokyo Institute of Technology, Japan \\ han.c.ad@m.titech.ac.jp, nasu.s.aa@m.titech.ac.jp
}

\begin{abstract}
Citizen-based Community Space (CS) is facing the continuity issues from a lack of human resources and the aging of managers. This study intends to clarify the relationship between the background experience of CS managers and their motivation for CS and consider how future participants can contribute to that. With the cooperation of 12 CSs created by Yokohama City's public subsidy, we interviewed 28 survey respondents who have worked as managers at them. As a result, five types of motivations for CS and five types of backgrounds are identified. The various relationship between motivation and background suggests the possibility of finding potential managers.
\end{abstract}

Keywords: Community space managers, Community activity experience, Motivation, Yokohama

eISSN: 2514-751X @ 2020 The Authors. Published for AMER ABRA cE-Bs by e-International Publishing House, Ltd., UK. This is an open access article under the CC BY-NC-ND license (http://creativecommons.org/licenses/by-nc-nd/4.0/). Peer-review under responsibility of AMER (Association of Malaysian Environment-Behaviour Researchers), ABRA (Association of Behavioural Researchers on Asians) and cE-Bs (Centre for Environment-Behaviour Studies), Faculty of Architecture, Planning \& Surveying, Universiti Teknologi MARA, Malaysia.

DOI: https://doi.org/10.21834/ajebs.v5i16.368 


\subsection{Introduction}

There are many community activities by citizens to solve their own social and regional problems in Japan. Generally, in Japan, there are activities driven by citizens to create and maintain their specific built environment. That behavior is called "Machizukuri" (Andre et al., 2009, pp33-34). Residents participate in volunteer activities to make their neighborhood clean and plant flowers for pleasant local townscape.

In recent years, citizens have realized that there were many opportunities to contribute to their community design and to participate in activities for improvement of the local area. There are also many examples of making and operating community spaces for community activity. Their community spaces work as a base-camp for sustaining community activity, supporting community tasks, and creating a better society. These community spaces improve various regional issues such as isolation of parenting peoples, lonely older person, and lack of community exchanges and inactivate local shopping street. (In this paper, we abbreviate community space to CS.)

In particular, Tokyo (Setagaya) is active in civic activities and community development. Nam (2014) explained the institutional and social background of CS using vacant houses in Setagaya, Tokyo. She/he also emphasized the leadership of NPOs and local coordinators in creating citizenled CS (Korean). Inoue et al., (2018) interviewed architects and operators on a community shared space designed by them to understand the spatial plan and the actual operating situation, and, described their self-evaluation of CS. They targeted eight cases of CS nationwide, including the case of Yokohama City (Japanese).

The CS created and operated by citizens is highly evaluated academically and socially. In Yokohama, community activities with making CS are common. The spaces for those activities are named "community café" and "Community Salon."

Yokohama has been practicing community development since the 1990s. In particular, they provide a unique subsidy system supporting the resident's improvement of their local living environment. It is called the "MACHIBUSHIN" project (Figure 1). Through this project, citizens propose, create, and maintain community spaces in various sites such as parks, promenades, and plazas. The local government supports not only building expense but also sending specialists who help to plan, design, and organize the space.
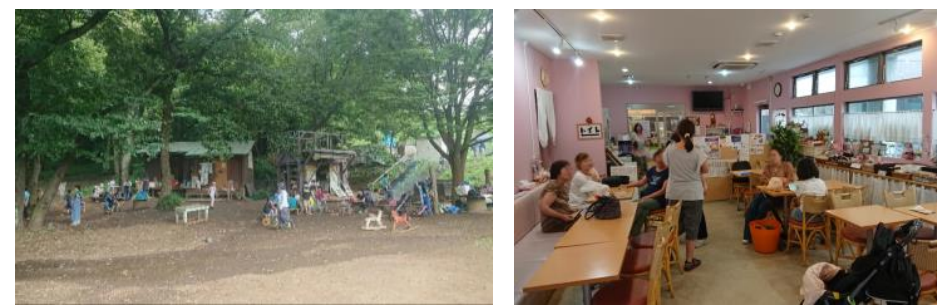

Figure 1: Picture of A "Play-park house"(left) and E "Cafe for the mentally handicapped"(right) (Source: Han Changhee, 2020)

There are some studies about CSs that explain as successful examples; however, CSs still have lots of tasks to work on. As you might know, Japan is a representative aging society (about 
$27 \%)$. The aging of community leaders sometimes causes difficulty in the activity continuation. Therefore, we focus on the situation of the limitation on human resources in the CS. This study assumes that CS managers' experience of Community activity and CS activity motivation are related.

\subsection{Literature Review}

Focusing on the role of CS managers as volunteers, previous studies in public health and social science are considerable. These studies describe the effects of community activities on the elderly, their correlation with functional disability through social participation, the effects of volunteer activities on improving the health of the elderly, and the effects of networking on individuals (Jerf et al., 2018; Fujiwara et al., 2005).

Also, Ram et al. (2010) found that volunteer activities have benefits for students, such as career experience and learning new things. Through the literature review, it has been confirmed that the participants of the volunteer activities had positive benefits such as health promotion, social contacts, career experience, and learning new things.

Previous studies tend to pay attention to the individual benefits of volunteering. However, they did not select or survey the main members (we call it the manager) of the volunteer organization. For the sustainable organization of CS, it is required that the smooth inviting of fresh managers and their continuous contributions. For that, we should focus on the manager's recognition of the reason why they volunteered for the organization. The viewpoints of this research are not only simple participants who volunteered but also the leading managers who organize and manage the community activity.

Yokohama's CS has not been discussed sufficiently, and community volunteer surveys also did not make a strict distinction between participants and leaders. This study's main objective is to identify the motivations that have influenced the manager's CS activities and provide a point of view for finding new potential CS managers and project practitioners.

\subsection{Methodology}

It was estimated that previous community activity experience would influence the motivation to participate in the actual project.

Although this study did not perform a quantitative analysis, there are limits to grasping a clear trend as there are not many CS managers currently in existence. However, we received research cooperation from managers selected based on the criteria presented in the paper, and the results were summarized. Qualitative research methods with interviews were sufficient for clarifying people's recognitions.

In this study, we selected all CSs executed on the same public subsidy, "MACHIBUSHIN" project, as well as designed and organized cases by citizens. From the selected CSs, 12 CSs kept on running management for more than five years. The 12CSs management groups agreed to cooperate with us. We interviewed 28 CSs managers, who have worked as managers at those 12 CSs. We requested an hour interview, and Table 2 shows the respondents and the details of 
the interviews and surveys. We explained the research objectives to the respondents and received permission to use the information obtained. Also, we passed the ethical research approval of our university.

Table 1: Survey summary

\begin{tabular}{cccccc}
\hline Respondent & Date of interview & $\begin{array}{c}\text { Duration of } \\
\text { interview }\end{array}$ & $\begin{array}{c}\text { Number of } \\
\text { interviewees }\end{array}$ & $\begin{array}{c}\text { Questionnaire } \\
\text { data }\end{array}$ & $\begin{array}{c}\text { Number of } \\
\text { questionnaire }\end{array}$ \\
\hline A & 2019.07 & $129(\mathrm{~min})$ & 2 & 2019.08 & 2 \\
\hline B & 2019.08 & $90(\mathrm{~min})$ & 2 & 2019.09 & 1 \\
\hline C & 2019.07 & $70(\mathrm{~min})$ & 4 & 2019.08 & 3 \\
\hline D & 2019.08 & $150(\mathrm{~min})$ & 2 & 2019.09 & 2 \\
\hline E & 2019.08 & $174(\mathrm{~min})$ & 3 & 2019.09 & 3 \\
\hline F & 2019.08 & $67(\mathrm{~min})$ & 2 & 2019.08 & 2 \\
\hline G & 2019.07 & $165(\mathrm{~min})$ & 3 & 2019.10 & 3 \\
\hline H & 2019.07 & $108(\mathrm{~min})$ & 3 & 2019.08 & 2 \\
\hline I & 2019.08 & $90(\mathrm{~min})$ & 4 & 2019.08 & 3 \\
\hline J & 2019.08 & $88(\mathrm{~min})$ & 1 & 2019.08 & 3 \\
\hline K & 2019.07 & $125(\mathrm{~min})$ & 3 & 2020.01 & 1 \\
\hline \multicolumn{5}{c}{ (Source: Han Changhee, 2020) } \\
\end{tabular}

The procedure of this study is as follows. Firstly, we summarize the activity in the CSs. Moreover, an overview of the CS managers and grasp of the managers' experience with community activity is done (chapter 4.1 and 4.2). Secondly, we identify what kind of motivations they had in their CS projects. Sentences related to motivation are extracted from the questionnaire and classified based on the background of the interview (chapter 4.3). Finally, in chapter 5 , we discuss the relationship between previous experience and motivation of managers based on the classification results, then consideration criteria for sustainability of CS management are proposed. Figure 2 explains the study flow.

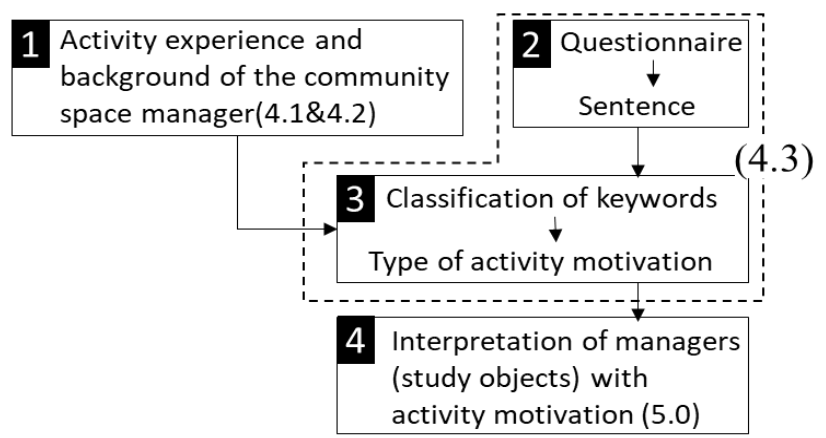

Figure 2: Methodology

(Source: Han Changhee, 2020)

We asked personal awareness and impressions about the motivation of participating in the project. Table2 shows the contents of the questions about the group activities in advance 
interviews. Table 3 shows the contents of the questionnaire. All surveys and interviews are conducted in Japanese, and this paper translates the results into English.

Table 2: Interview questions for the project group

\begin{tabular}{cl}
\hline No. & \\
\hline 1 & What kind of community activity did this group do before working on the CS project? \\
\hline 2 & During the project, how did the government, experts, and other residents exchange opinions? \\
\hline 3 & What kind of activities did you do after the community space was created? \\
\hline 4 & Are there any newly discovered local issues or activities while operating? \\
\hline 5 & How do you now relate to the people who participated in the project? \\
\hline
\end{tabular}

(Source: Han Changhee, 2020)

Table 3: Questions used in the survey for personal

\begin{tabular}{cl}
\hline No. & \multicolumn{1}{c}{ Questionnaire } \\
\hline 1 & What motivates participants to create a community space project? \\
\hline 2 & $\begin{array}{l}\text { What was your interest in a community activity before participating in this project? (If yes, please } \\
\text { explain what kind of activity you had done) }\end{array}$ \\
\hline 3 & How are you interacting with the people you know from this project? \\
\hline 4 & What do you think is worthwhile about doing projects or community activities? \\
\hline
\end{tabular}

(Source: Han Changhee, 2020)

\subsection{Results}

\subsection{Activity in Community Space}

Table 4 shows the activities in each CS. Some of these cases are difficult to implement in existing public facilities. For example, Case "G" manages a park under the responsibility and leadership of citizens' organizations, and they allow children to play with the ball freely that are not permitted in the usual public park. Additionally, the Case "I" provide the make-up service, which is related to personal interest and challenging to produce in existing public facilities, and the Case "K" offers opportunities to interact with international students and the community.

Case "E," Case "G," and Case "H" have a similarity that spaces are located close to the residents' houses for facilitating their exchanges. Case "B" and Case "L" promotes interactions through cultural activities. In the other four cases, the activities are provided for helping elderly neighbors (Case "C" and "F"), people with mental disabilities (Case "D"), and parenting parents (Case "J").

12 cases of CS have a variety of activities and spaces as bases for interactions and activities. From the verbal surveys, we extracted the sentences about the motivation and analyzed them using the Affinity Diagram Method.

We know that the age of users varies depending on the content of CS. Relatively young users will use G, I, K, and J. The purpose of the other CSs was an extension of existing community activities and welfare activities. 
Table 4: Contents of community spaces

\begin{tabular}{|c|c|}
\hline Case & Activity contents \\
\hline A & $\begin{array}{l}\text { This group creates an environment where children play freely. They maintain the play-park and } \\
\text { act as play leaders. }\end{array}$ \\
\hline B & $\begin{array}{l}\text { This group plans the tea house and garden where people can experience Japanese culture and } \\
\text { operates the activities of Japanese traditional tea ceremonies. }\end{array}$ \\
\hline C & $\begin{array}{l}\text { The group provides places where the elderly can easily visit and take meals. Local business } \\
\text { activities in the shopping district are also progressing. }\end{array}$ \\
\hline D & The group provides places and meals for people who have mental illness and mental disabilities. \\
\hline $\mathbf{E}$ & $\begin{array}{l}\text { The residents' association operates and manages the space where people can use without } \\
\text { charge. }\end{array}$ \\
\hline $\mathbf{F}$ & The group provides places where the elderly can easily visit and take the meal. \\
\hline G & $\begin{array}{l}\text { The group supervises the park for children's safety use. This place is a base for various community } \\
\text { activities. }\end{array}$ \\
\hline H & $\begin{array}{l}\text { They make a place where people can gather. Furthermore, they are engaged in revitalizing } \\
\text { shopping streets and creating attractive communities. }\end{array}$ \\
\hline $\mathrm{I}$ & They make places where women can refresh, and they provide make-up classes. \\
\hline $\mathbf{J}$ & $\begin{array}{l}\text { They provide a multiple-purpose place depend on users. The place also acts like the rest space } \\
\text { for families with young children. }\end{array}$ \\
\hline K & $\begin{array}{l}\text { They provide a guest-house where foreign travelers can come. Various events for international } \\
\text { exchange are held in the space. }\end{array}$ \\
\hline $\mathbf{L}$ & $\begin{array}{l}\text { The local museum displays materials for learning cultural history and promotes exchanges among } \\
\text { residents. }\end{array}$ \\
\hline
\end{tabular}

(Source: Han Changhee, 2020)

\subsection{Activity Experience and Background of the Community Space Manager}

28 people of the CS managers cooperated with the questionnaires. Figure 3 shows the number of each gender, female (18), and male (10). Female is slightly higher than the male. However, considering the volunteer staff participating in the activity, the proportion of females is twice and higher than males. Figure 4 shows the age of managers. There are 13 managers in their 70 s and above, and $60 \%$ of all managers are more than $60 \mathrm{~s}$. These results indicate that limited neighbors are involved, lack of human resources will occur in the future if the new managers do not participate in these.

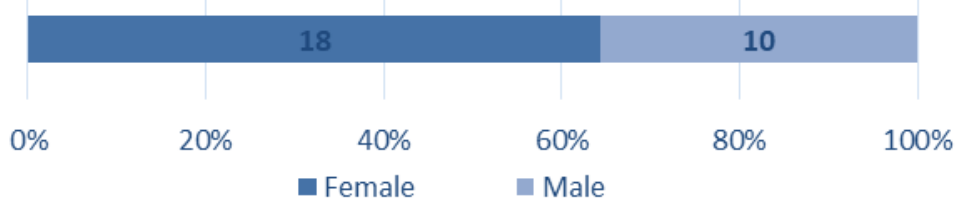

Figure 3: Gender of managers

(Source: Han Changhee, 2020) 


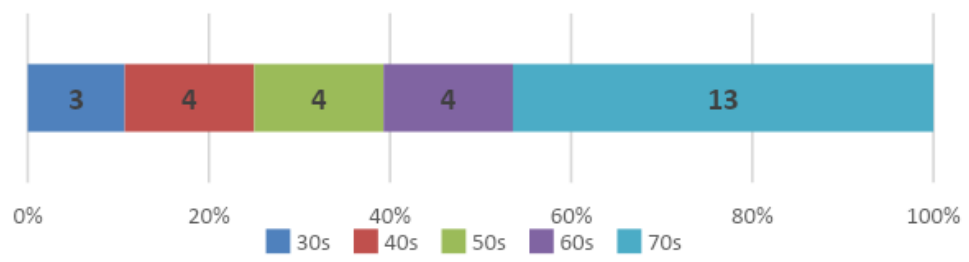

Figure 4: Age of managers

(Source: Han Changhee, 2020)

Figure 5 shows the answer to questions about community activity experience before participating in the CS project. It indicates that 24 managers said they had experience in community activities, while the other rest of them had no experience. We determined the respondents' self-evaluation of community activities as the most important criterion for classification. Also, we judged the degree of their dedication based on the length of their activities (Five years or more). We categorize experiences of community activities based on spontaneity because community activities included participation and help by request. As a result, five categories were extracted, and these are shown in Figure 6 with typical samples.

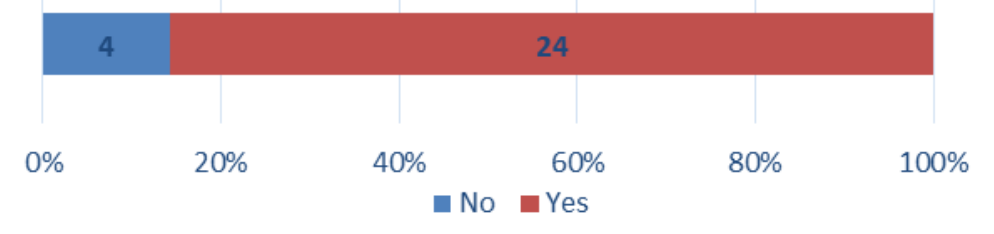

Figure 5: Experience with community activities before joining the CS project

(Source: Han Changhee, 2020)

CA-Co indicates the leading role in conventional Japanese community activities, such as social welfare activities, community associations, and youth advisors throughout many years. These are activities in the existing group, such as the residents' association and disaster prevention activities. This type is closely related to existing community activities.

CA-Pr indicates that the activity CA-Pr works on independently for specific purposes: they work on the community activity to run the CS project. Those CS projects are premised on solving local issues. So, in some cases, they worked with existing community organizations. However, the difference is that they started their activities for unique goals, and they have an independent group. This type of case may include both those with and without the experience of conventional community activities. The comments $\mathrm{A} 1$ and $\mathrm{H} 1$ indicate unique goals. The two types below are for those with previous community activities.

$\mathrm{CA}-\mathrm{Pa}$ indicates the experience in community activity with the passive attitude of people. People in this category have participated in community activities like CA-Co, but these are transient and requested activities. For example, their experience was based on the responsible system at the Neighborhood Association (JICHIKAl) and participating in the Parent-Teacher 
Association (PTA) only when their children were in school. The comments F1 indicates typical characteristics. It was a little relationship.

\begin{tabular}{l} 
CA-Co (12) Community Activity experience in Conventional \\
community groups based on local area. \\
\hline $\mathrm{C} 1$ I am a community association and youth advisor. \\
C2 We have beenworking to solve the problems of the elderly. \\
We had talks and dinner parties with the elderly. And offered \\
pick-upservice.
\end{tabular}

\begin{tabular}{l} 
CA-Pr (7) Community Activity related to CS Projects without \\
existing organizations. \\
$\begin{array}{l}\text { A1 At the time, I wasworking to create an environment where } \\
\text { children could play freely. }\end{array}$ \\
$\begin{array}{l}\mathrm{D} 2 \begin{array}{l}\text { After retiring, I thought about what I could do to the community. } \\
\text { I started a volunteer activity form whatever I could do. }\end{array} \\
\mathrm{H} 1 \text { I became interested in creating a place where I could dowhat I } \\
\text { wanted to do, so I became avolunteer member }\end{array}$ \\
\hline
\end{tabular}

CA-Pa (5) Passive Experience with community activities on
request.

\begin{tabular}{|ll|}
\hline F1 I was not interested in the Neighborhood Association, sol only \\
came to the Neighborhood Association when I became an officer.
\end{tabular}

\begin{tabular}{l} 
Ne-At (2) have experience but, Negative Attitude toward \\
Community activity \\
\begin{tabular}{|l|}
\hline E1 I was afraid of community activities So, I was not interested in \\
community activities.
\end{tabular} \\
\hline \hline I3 I had little involvement with the community. I was not interested. \\
\hline
\end{tabular}

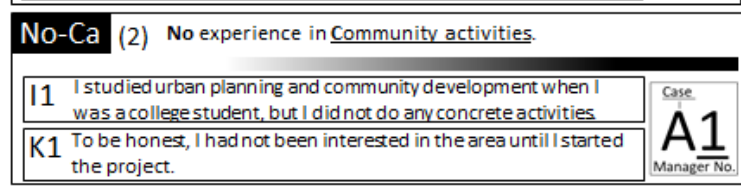

Figure 6: Type of community activity experience (Source: Han Changhee, 2020)

Ne-At indicates they have Community activity experience, but with a negative attitude toward community activity. The four types have had differences in the positiveness of community activity.

No-CA states managers without the experience of community activity. The existence of this case indicates that people without experience can be managers for CS.

Some managers have been involved in community activities for more than 50 years. Many managers had an experience of past community activities, and some of them had a negative impression. We should pay attention to the people with a comment like E1 as "I was not interested in a community activity." They are now working as CS managers and doing community activity. 
Depending on people and management of the CS, the person who had no experience of community activity, and the person who had a negative attitude on community activity is now active. Also, on the other hand, some people had no experience of community activity before the project.

\subsection{Motivation to join for the project}

From the responses to the questionnaire, 72 cases were extracted as a sample unit (sentence) for analysis, and the number of sample units related to motivation is 43 . Nine cases were connected with the subject's background and analyzed. The original sentence in Japanese is the unit of analysis, and Figure 7 shows the translated sentences. As a result, five types of motivation for CS project participants were classified.

From the contents of Figure 7 (H1), the motivation of $\mathrm{H} 1$ is summarized as 'Personal Interest.' Through the analysis of all responses of questionnaires, five motivations are extracted (Figure 8). The Mo-Co explains that social contribution is the motivation of the CS project. Specifically, they wanted to change the local situation and had a high attachment to the local community.

Mo-In indicates motivation with a personal interest in creating or making CS, community development, and relationships. In some cases, they participated in activities that could lead to their re-employment. In the case of Mo-PI, motivation arises in the process of carrying out a CS plan. Mo-Gr indicates motivation for the extension of the organization's existing activities. In Mo$\mathrm{Re}$, people got invitations from the existing members to participate in the CS project. Depending on people, some cases have multiple motivations, but some cases have personally weak motivations.

\section{Summary}

H1 has interests in the place of their want to do and community development. Also, she wanted to have the experience helpful for reemployment.

H1: (i) "I was interested in what I wanted to do and where I could do activities," and became a volunteer member. I studied architecture when I was a university student. So,(ii) "I was also interested in community development,"(iii) "I wanted to have fun and competent experience with children for re-employment."

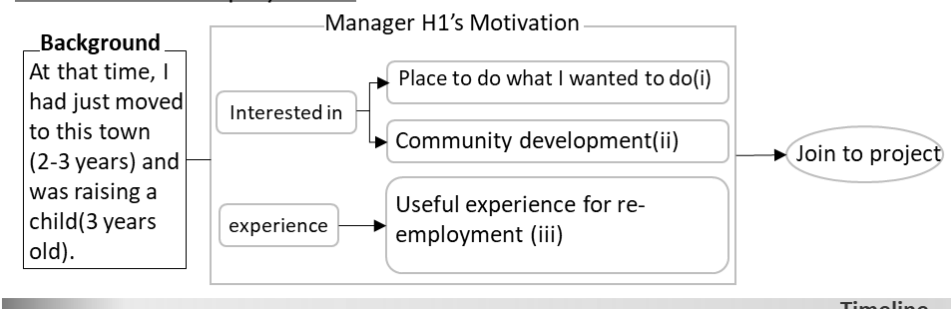

Figure 7: Analysis example for $\mathrm{H} 1$ motivation

(Source: Han Changhee, 2020) 


\begin{tabular}{l}
\hline Mo-Co (7) Motivation for Contribute \\
$\begin{array}{l}\text { I want to do something by looking at the local } \\
\text { situation. }\end{array}$ \\
C3-i,D2-ii,F2-i \\
I want to contribute because II have ived in this area \\
for a lifetime. \\
\hline I want to help something in this local area. G2-i,L3-iii \\
\hline
\end{tabular}

\begin{tabular}{|l|}
\hline Mo-In (9) Motivation for Interesting something \\
\hdashline I was interested in space making, space. G2-ii,G3-ii, H1-I \\
\hdashline I was interested in community development, \\
relationship making, activities, and local history and \\
culture. H1-ii,G3-v,J3-ii,L1-ii \\
\hdashline I wanted to have a career experience while raising \\
children. \\
H1-iii,I2-i
\end{tabular}

\begin{tabular}{l}
\hline Mo-PI (4) Motivation for realized a Plan \\
\hline I had a plan I wanted to realize. A1-iii,D2-i, J1-i,K1-i \\
\hline
\end{tabular}

\begin{tabular}{|} 
Mo-Gr (15) Motivation for activities of the Group \\
I thought we needed a place to be more active. \\
A1-i,A2-i,B1-i,C2-i,I2-ii, I2-V,I3-i,J2-I,L1-i \\
C1-ii,E1-i,E2-i,G1-i,G2-i,G3-iii \\
It was planned during the activities of the group. \\
C1,
\end{tabular}

Mo-Re (8) Motivation for Request by Community leader I started activities by calling out.

C1-i,D1-i,E3-I,H3-i, I1-I,J3-i, L3-i,L2-i

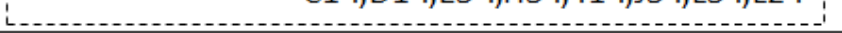

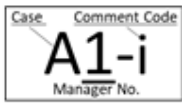

Figure 8: The type of motivation (Source: Han Changhee, 2020) 


\subsection{Discussion}

Table 5 shows the relationship between respondents' experiences of previous community activities and motivations for $\mathrm{CS}$ activities. In this table, motivations are lined based on its attitude from the internal (Mo-Co, Mo-In) to the external (Mo-Re). Motivational attitudes are assumed to have a less gradual impact, rather than a clear distinction. As a relative concept, the motivation attitudes are divides into what has a strong external influence and what does not.

Firstly, we discuss the distribution of cases. Most of the experiences are on the upper three lines of the table; the first two experiences mean a positive attitude for community activity, so it seems to be easy to bring motivations for CS. On the other hand, motivations are spreading over broader types. Case $\mathrm{H}$ is located at Mo-In. In addition, the CS case $(A, B)$ is also focused on project progress and group activities (Mo-Pr, Mo-Gr). In contrast to it, cases C, D, G, and H locate in a broader area. And the diversity of motivations by each manager differ between CSs. The motivations of managers tend to be simplified in case $F, I$ and $K$. But in the case $C, G$, and $L$ that have various motivational factors, motivations of each manager are also diverse. We think this is likely to present the features of the CS that the motivation may be diverse.

Secondly, we discuss the relationship between the existence of experience and motivations. The upper two experiences in the table have an attitude to join community activities, so they have many types of motivations. In contrast, it, $\mathrm{CA}-\mathrm{Pa}$, No-CA, and Ne-At experience seem to be the low and passive attitude for joining community activity. However, even though in those attitudes, broad types of motivations from CA-Pa experience, two Mo-Gr motivation from Ne-At experience, and two motivations from No-CA experience were extracted. As a consequence, there is a possibility that the limitations, such as a shortage of human resources, are resolved by actively requesting people without previous community activities. In some cases, they found motivation with personal interest (Mo-In) during CS activity. For example, case $\mathrm{J} 3$ had a motivation with personal interest as well as a motivation by request. 12 at $\mathrm{CA}-\mathrm{Pa}$, who used to be passive in community activity, had motivation with personal interest as well as a motivation for the group. From these results, the transition of attitudes in experience and motivation are confirmed.

Lastly, unexpected cases are discussed. In the case of $\mathrm{Ca}-\mathrm{Co}$, it did not have any motivation to pursue a new plan. In the case of $\mathrm{H} 1$, it seems to be possible to have various motivations such as Mo-In through participation in CS activities, despite the fact that the experience of community activities itself was passive (CA-Pa).

As a result of the discussion, many people with several motivations related to community activities are participating in CS management. However, CS management depended on people's resources with community activity experience. More participation of people without previous experience and with passive attitudes are expected for the continuation of CS and community development. Therefore the diversity of motivations and experiences can be one of the effective indexes for identifying CS with tolerance for participating peoples. 


\begin{tabular}{|c|c|c|c|c|c|}
\hline & Internal & & & & Externa \\
\hline Experience & Mo-Co & Mo-In & Mo-PI & Mo-Gr & Mo-Re \\
\hline CA-Co & $\begin{array}{l}\text { C2,C3, } \\
L 3, F 2\end{array}$ & $\begin{array}{l}\text { G3,G3, } \\
\text { L1,J3 }\end{array}$ & & $\begin{array}{l}\mathrm{C} 1, \mathrm{C} 1, \mathrm{C} 2, \\
\mathrm{C} 3, \mathrm{~L} 1\end{array}$ & $\begin{array}{l}\text { C1,D1,E3, } \\
\text { J3,L2,L3 }\end{array}$ \\
\hline CA-Pr & G2,D2 & $\begin{array}{l}\mathrm{G} 2, \mathrm{H} 1, \\
\mathrm{H} 1, \mathrm{H} 1\end{array}$ & A1,D2,J1 & $\begin{array}{l}\text { A1,A2,B1 } \\
\text {,B1,G2 }\end{array}$ & \\
\hline $\mathrm{CA}-\mathrm{Pa}$ & $\mathrm{F} 1$ & 12 & & $12, E 2, J 2$ & H3 \\
\hline Ne-At & & & & $\mathrm{E} 1, \mathrm{I3}$ & a \\
\hline No-CA & & & K1 & n & 11 \\
\hline
\end{tabular}

Table 5: Relationship between respondents' experiences of previous community activities and motivations for CS activities

(Source: Han Changhee, 2020)

\subsection{Conclusion}

This study provides a perspective for finding potential managers. For this purpose, we grasped the Motivation of CS activities and considered them by linking them from the experience of Community activity. We conducted interviews and questionnaires with managers who have managed CS in Yokohama for over five years. As a result of the survey, we were able to confirm their background and impression of community activities along with motivations. Furthermore, we checked the age and gender trends in CS managers. Community activities divided into five types. The five types are conventional community activity (CA-Co), experienced community activities with this project (CA-Pr), experienced but passive group (CA-Pr), negative (Ne-At), and nonexperienced group (No-Ca). Also, CS activities toward CS managers' motivations are divided into five types. The Five types are contributing to the local community(Mo-Co), active or personal interest(Mo-In), motivation for realization(Mo-PI), motivation because of a group (Mo-Gr), and request from the locals (Mo-Re). Managers with experiences of community activity tended to have multiple motivations. In a few cases, peoples without any experience or positive feeling with community activity can contribute to making new CS. 
In conclusion, most of the current CSs depends on the person who experienced community activities. It is necessary to invite broader participants and bond inexperienced people and young people with existing managers for the more prolonged continuation of citizen-based community spaces. We would like to promote research on motivation theory in addition to subdividing motivation types. Also, NE-At and CA-Pa people need to carry out follow-up research and research on when they felt their activity motivation.

\section{Acknowledgment}

The authors are grateful to CS managers in Yokohama for their cooperation in the survey. Moreover, special thanks to those who sent us the questionnaires and with a lovely letter. We look forward to their activity and the active and healthy future.

\section{References}

Andre S., Koizumi H., Miyamoto A.,(2009). Machizukuri, civil society, and community space in Japan, The Politics of Civic Space in Asia Building Urban Communities, Routledge Contemporary Asia Series, Chapter 3

Nam J., (2014). Creating Local Community Core Utilizing Empty Houses-focusing on the Local Common House-, Journal of the Architectural Institute of Korea Planning \& Design, 30-11(Korean)

Inoue G., Hara R., Sakurai H., Almazan J., (2018).THE DESIGN AND MANAGEMENT OF COMMON SPACES FOR LOCAL COMMUNITIES: A case study on eight renovation projects, Journal of Architecture and Planning (Transactions of AIJ), (754), 2453-2463

Jerf W., Zhuoni Z., Kim T., (2018). Volunteering and health benefits in general adults: cumulative effects and forms, BMC public health, 18:8

Fujiwara Y., Sugihara Y., Shinkai S., (2005). EFFECTS OF VOLUNTEERING ON THE MENTAL AND PHYSICAL HEALTH OF SENIOR CITIZENS SIGNIFICANCE OF SENIOR-VOLUNTEERING FROM THE VIEWPOINT OF COMMUNITY HEALTH AND WELFARE. Japanese journal of public health, Vol. 52, Issue 4, 293-307 (Japanese)

Ram A., Karen A., Kirsten H., Debbie H., Femida H., (2010). Motivations and Benefits of Student Volunteering: Comparing Regular, Occasional, and Non Volunteers in Five Countries. Canadian Journal of Nonprofit and Social Economy Research, Vol.1, No 1, 65-81

United Nations (2017). World Population Prospects: the 2017 Revision:

https://www.un.org/development/desa/publications/world-population-prospects-the-2017-revision.html (2020/02/12, Access)

Cabinet Office Government of Japan, Special birth rates in countries around the world:

https://www8.cao.go.jp/shoushi/shoushika/data/sekai-shusshou.htm(2020/02/12, Access)

Cabinet Office Government of Japan, the Aging rate in Japan and Asian countries:

https://www8.cao.go.jp/kourei/whitepaper/w-2018/html/gaiyou/s1_1.html (2020/02/12, Access)

Yokohama, Total Fertility Rate: https://www.city.yokohama.Ig.jp/kurashi/sumai-kurashi/jutaku/shiryo/toukei/jijou3-7.html (2020/02/12, Access) 